\title{
O DIREITO ENGENDRANDO IDENTIDADES TRANS: ANÁLISE DOS VOTOS DE INDEFERIMENTO DA RETIFICAÇÃO DE REGISTRO CIVIL NO TJRS
}

THE LAW ENGENDERING TRANS IDENTITIES:

ANALYSIS OF VOTES AGAINST THE RECTIFICATION OF BIRTH REGISTRATION IN TJRS

Róger Ruoso Teixeira e Gabriela Felten da Maia²

RECEBIDO EM: 11/06/2017 | APROVADO EM: 22/07/2017

DOI: $10.5902 / 2317175827622$

\begin{abstract}
RESUMO
O presente trabalho se propõe a analisar as decisões do Tribunal de Justiça do Rio Grande do Sul - TJRS, proferidas a partir do ano de 2010, em sede recursal de apelação, referentes às demandas que objetivavam a retificação de sexo/gênero do registro de nascimento de pessoas trans. Objetivou-se identificar, através dos votos proferidos pelos operadores do direito (Desembargadores), a existência de produção e reprodução de tecnologias de gênero, de discursos nutridos de apropriação de saberes médicos e utilização de representações sobre o que é ser homem e ser mulher. Mediante a análise hermenêutica, com o auxílio das teorias feministas sobre sexo, gênero e transexualidade, analisou-se seis decisões proferidas do TJRS que, em sede de apelação, não reconheceram o direito à retificação de sexo/gênero no registro de nascimento de pessoas trans. A referida análise demonstrou que as decisões dos julgadores fundamentaram o não acolhimento dos pedidos com base nas representações socialmente compartilhadas de gênero, eivadas de discurso científico, dos julgadores sobre o tema em discussão nos pleitos.
\end{abstract}

Palavras-chave: gênero, transgeneridade, direito, retificação de registro civil.

1 Graduando em Direito da PUCRS. E-mail: rogerrteixeira@gmail.com.

2 Psicóloga do Centro de Referência Especializado de Assistência Social, Cachoeira do Sul. Doutoranda em Antropologia Social pela UFRGS. Mestre em Ciências Sociais pela UFSM. E-mail: gabryelamaia@gmail.com. 


\begin{abstract}
This work aims to analyze the decisions of the Justice Court of the state of Rio Grande do Sul TJRS - that have been ruled since 2010 referring to demands of rectification of gender/sex in birth registration of transgender people. Our objective was to identify, through the votes passed by the judges, the incidence of production and reproduction of technologies of gender, speeches carrying appropriation of medical knowledge and the use of representation of what being a man or a woman is. By means of hermeceutic analysis, and considering the feminist theories of sex, gender and transsexuality, we analyzed six decisions made by TJRS that, as an appeal court, didn't recognize the right to rectification of sex/gender in the birth registration of trans people. This analysis showed that the judges' decisions substantiated the non-recognition of the right based on representations that are socially shared about gender, also affected by scientific discourse.
\end{abstract}

Keywords: gender; transsexuality; law; rectification of birth registration.

\title{
1 Introdução
}

No Brasil, a luta social pelo reconhecimento da identidade de gênero também passa pelo reconhecimento jurídico, entre a promulgação de micronormatizações do uso do Nome Social, os processos de retificação civil e o debate sobre Projetos de Leis que versam sobre a identidade de gênero. Como o país não possui legislação específica que regule o direito à identidade de gênero, a exemplo de vários países da América Latina e da Europa que asseguram direito às pessoas trans ${ }^{3}$, a lacuna legislativa coloca o judiciário como o principal caminho para alcançar o direito à identidade.

Essa centralidade do Poder Judiciário compõe as demandas dos movimentos trans nos debates internacionais e nacionais para o reconhecimento da diversidade de gênero (SUESS, 2014). A incorporação da luta por reconhecimento da identidade de gênero a partir da estratégia judicializante vem sendo compreendida, como destaca Bento (2014), como uma forma de criar uma situação jurídica que visibiliza demandas da população trans, tornandose uma forma de tornar essa população legível (SCOTT, 1998).

O direito torna-se uma arena, um recurso político para a visibilidade das demandas da população trans de tal modo que o reconhecimento dos direitos e da cidadania trans, como destaca Bento (2008), tem demandado cada vez mais respostas do Direito. O judiciário, portanto, tem sido o caminho para que

3 Na Europa encontramos legislações de reconhecimento da identidade de gênero no Reino Unido, Espanha, Portugal, Suécia, Malta, Islândia, Estónia, Bielorrússia, Polônia, Alemanha, Áustria, Hungria, Dinamarca; e na América Latina, na Argentina, Venezuela, Uruguai, Bolívia, Equador. Em alguns países, as legislações procuram garantir a identidade de gênero como um direito humano das pessoas trans sem condicionar ao procedimento de redesignação sexual, algumas vão mais além e dispensam qualquer necessidade de apresentação de laudo comprovando a transexualidade ou exigência de realização de hormonização. Mas é a legislação da Argentina, considerada a mais corajosa por seguir a perspectiva da despatologização de gênero, que reconhece a autodeterminação do sujeito, sem exigir tratamentos hormonais, cirurgia de redesignação sexual, laudos médicos ou psicológicos ou comprovante de profissionais da saúde para que a pessoa trans tenha seus documentos retificados. (PEREIRA, 2014, Disponível em <http://www.esquerda.net/ dossier/o-reconhecimento-da-identidade-de-genero-como-processo-emancipatorio-percursos-legais/33954 >, Acesso em 20 jul. 2016). 
o direito das pessoas trans à identidade seja efetivado, e essa estratégia de formalização do acesso aos direitos à identidade através da demanda de retificação do registro civil é acompanhada por uma tradução no campo jurídico.

A entrada no campo jurídico, até as decisões dos pleitos de retificação de registro civil, parece ser acompanhada de tensões entre agentes sociais envolvidos nesse processo (Juízes, Desembargadores, Advogados, Defensores Públicos, Ativistas e Profissionais da área Psi e do Serviço Social). Rifiotis (2008) e Rifiotis e Matos (2010) destacam que a judicialização se apresenta, ao mesmo tempo, como uma solução e um problema quando se trata de lutas sociais por reconhecimento, porque entendem ser uma forma de garantia do acesso à justiça e da cidadania, porém o campo jurídico não é um domínio neutro no qual as agendas dos movimentos e ativismos são projetadas sem que ocorra processos de tradução.

Diante de tal contexto, este artigo realiza uma análise hermenêutica, com o auxílio das teorias feministas, de decisões do Tribunal de Justiça do Rio Grande do Sul (TJRS) que não reconheceram o direito à identidade de gênero. Conforme dados obtidos junto ao site do TJRS, verificou-se que foi julgado o primeiro recurso de apelação relativa ao mérito do pedido de retificação de gênero no ano de 2006. Desde lá, até o ano de 2017, verificou-se que o TJRS julgou o mérito de 46 recursos de apelação, dos quais 40 reconheceram o direito à identidade de gênero e 7 não autorizaram a retificação pretendida.

Importa referir que até a metade do ano de 2016 a Sétima Câmara Cível do TJRS, diferente do entendimento adotado pela Oitava Câmara Cível, julgava no sentido de que só era possível o deferimento do pedido de retificação de gênero quando devidamente comprovada a realização da cirurgia de redesignação sexual. A Oitava Câmara Cível, por sua vez, desde o ano de 2006, autorizou a retificação de gênero em todos os processos, adotando o entendimento de que estando presente a condição de transgênero, esta, por si só, autoriza a retificação pretendida. Assim, chama atenção analisar os fundamentos produzidos pelos operadores do direito que compunham a Sétima Câmara Cível nas decisões que não autorizaram a retificação de gênero.

O presente artigo é um recorte de trabalho de curso sobre o tema da (in) aplicabilidade da legislação constitucional e internacional pelos desembargadores do TJ-RS em seus votos de indeferimento dos processos de retificação de documentos de pessoas trans. Refletir-se-á neste trabalho, a partir de discussão feminista de gênero, as concepções de gênero nas decisões judiciais. Por isso, inicia-se pensando o processo de judicialização do direito à identidade e as tensões presentes na tradução dessa demanda no campo jurídico, para, em seguida, refletir o Direito como uma tecnologia de gênero, analisando os votos dados pelos desembargadores em suas decisões de indeferimento. 


\section{A cidadania trans e a judicialização do direito à identidade}

Alguns autores têm abordado o protagonismo do Poder Judiciário, das leis e do direito no contexto contemporâneo (RIFIOTIS \& MATOS, 2010), refletindo sobre o direito como um importante elemento na construção da legitimidade das demandas sociais dos movimentos sociais, guiadas pela perspectiva dos direitos humanos (RIFIOTIS, 2010). Para Rifiotis e Matos (2010) e Rifiotis (2014), essa movimentação possibilita tanto conformar normas e jurisprudências, como torna-se uma forma dos movimentos sociais visibilizarem e buscarem respostas às suas demandas, chamando a atenção para a centralidade do Direito na leitura dos Direitos Humanos.

Em Porto Alegre, RS, há uma experiência de mutirão que promove o acesso à retificação de registro civil das pessoas trans, através do projeto "Direito à identidade: viva seu nome!", desde 2013, encontrando-se em sua oitava edição. Esse projeto envolve diferentes agentes sociais, ativistas trans, profissionais e pesquisadores de áreas como a Psicologia, o Serviço Social, o Direito, organizações não-governamentais, núcleos de pesquisa e órgãos do campo judicial. Realizado pelo Serviço de Assessoria Jurídica Universitária (SAJU), através do grupo G8-Generaizando (Grupo de Direitos Sexuais e de Gênero), da UFRGS, em parceria com a Associação de Travestis e Transexuais do Rio Grande do Sul (Igualdade-RS), do Núcleo de Pesquisa em Sexualidades e Relações de Gênero (NUPSEX), da UFRGS, o Instituto Brasileiro de Transmasculinidade (Ibrat) e da Defensoria Pública do Estado do Rio Grande do Sul, procura mobilizar coletivamente pessoas trans a protocolarem os pedidos de retificação de registro civil. Anualmente, produz-se um evento para discutir o processo de retificação e o direito à identidade, com o objetivo não apenas de criar mais uma demanda judicial, mas que o momento também seja marcado por uma linha política, ao procurar chamar a atenção do legislativo e do judiciário.

Movimentos como esses emergem em um contexto em que não há regulamentação legislativa, mas a existência de normas de nível constitucional e supranacional, em especial pelos direitos expressos à liberdade, à igualdade, à intimidade, à não discriminação, à autodeterminação, dos quais se extrai o direito à identidade de gênero. Esse entendimento ganha maior força quando visualizado a partir do ordenamento internacional, em especial pelos Direitos Humanos e pelos Princípios de Yogyakarta, que norteiam a aplicação da legislação internacional de Direitos Humanos em relação à orientação sexual e à identidade de gênero. Os referidos princípios, ainda que não tenham sido resultado dos esforços comuns entre os Estados, são um dos mais importantes instrumentos e preceitos da legislação internacional de Direitos Humanos em relação à orientação sexual e à identidade de gênero.

É nesse contexto que o Supremo Tribunal Federal (STF) já reconheceu a aplicabilidade e validade dos aludidos princípios no ordenamento jurídico brasileiro no ano de 2015, quando do julgamento do Recurso Extraordinário 477.544 que debateu a constitucionalidade da união civil entre pessoas do 
mesmo sexo . Nesse caminho, também há a decisão exarada pelo Superior Tribunal de Justiça (STJ) no primeiro semestre de 2017, que analisa se pessoas trans possuem o direito à alteração do registro civil independentemente da realização de intervenção cirúrgica. A Corte Cidadã, em tal caso, o qual não se obteve acesso aos dados de identificação em razão do segredo de justiça decretado, entendeu que o direito à retificação de gênero da pessoa transexual não pode estar condicionada à realização de cirurgia, sendo necessário, entretanto, a comprovação judicial da identidade de gênero.

Na Suprema Corte também tramita, desde 2009, a Ação Direta de Inconstitucionalidade (ADI) $n^{\circ} 4.275$, que discute a possibilidade de retificação do nome e gênero no registo civil independente da cirurgia de redesignação sexual. O STF ainda não apresentou resposta conclusiva à questão, acrescentando-se, todavia, que no dia 07 de junho de 2017 iniciou o julgamento da ADI 4275. Na referida sessão inaugural dos debates na Suprema Corte, o representante da Procuradoria Geral da República, autora da aludida demanda, reforçou que no caso em debate está se discutindo sobre a existência de um direito fundamental à identidade de gênero com base nos princípios da dignidade da pessoa humana (artigo $1^{\circ}$, inciso III), da igualdade (artigo $5^{\circ}$, caput), da vedação de discriminações odiosas (artigo $3^{\circ}$, inciso IV), da liberdade (artigo $5^{\circ}$, caput) e da privacidade (artigo $5^{\circ}$, inciso X), todos da Constituição Federal. Participam na condição de amici curiae o Instituto Brasileiro de Direito de Família, o Laboratório Integrado em Diversidade Sexual e de Gênero, Políticas e Direito, o Centro Latino-Americano em Sexualidade e Direitos Humanos (CLAM) e o Grupo Dignidade - Pela Cidadania de Gays, Lésbicas e Transgêneros, este último representado na Suprema Corte pela primeira advogada transexual da região sul do país, Gisele Alessandra Schmidt e Silva.

Essa discussão demonstra o que Rifiotis (2015) chama de judicialização das relações sociais, um termo que designa "os processos que se visibilizam através da ampliação da ação do Estado em áreas de 'problemas sociais' como mecanismo de garantia e promoção de direitos". O autor (RIFIOTIS, 2008) lembra que, nas sociedades democráticas, a forma de legitimidade hegemônica reside na crença na legalidade, o que aponta para o processo de judicialização das relações sociais, isto é, a crescente invasão do direito, das leis e do Poder Judiciário na organização da vida social (DEBERT, 2010; RIFIOTIS, 2008, 2014; RIFIOTIS \& MATOS, 2010; SCHUCH, 2008).

O avanço do judiciário como uma possibilidade de resposta à defesa e conquista de direitos, especialmente para setores mais vulneráveis, faz com que as sociedades estejam cada vez mais, nas palavras de Debert (2010), enredadas na semântica da justiça. A autora, seguindo as considerações de Werneck Vianna, argumenta que

Nas sociedades ocidentais contemporâneas, essa invasão do direito não se limita à esfera propriamente política, mas tem alcançado a regulação da sociabilidade e das práticas sociais em esferas tidas, tradicionalmente, como de natureza estritamente privada, 
como são os casos das relações de gênero e o tratamento dado às crianças pelos pais ou aos pais pelos filhos adultos. Os novos objetos sobre os quais se debruça o Poder Judiciário compõem uma imagem das sociedades ocidentais contemporâneas como cada vez mais enredadas com a semântica jurídica, com seus procedimentos e com suas instituições (DEBERT, 2010, p. 486-487).

Schuch (2008), a partir de seu estudo sobre a mudança legal no campo da proteção à infância e à adolescência, destaca que o discurso dos direitos como um capital simbólico privilegiado no contexto das sociedades democráticas ganha centralidade através de um protagonismo dos órgãos judiciais e passa a compor a linguagem das lutas políticas, pois "na esfera judicial e na esfera extrajudicial do trabalho dos órgãos de justiça, é interessante perceber como a ideia dos 'direitos' passa a se colocar como fundamento para a garantia de elementos básicos para a vida das pessoas, como saúde, liberdade etc." ( $\mathrm{SCHUCH,} \mathrm{2008,} \mathrm{p.} \mathrm{14).}$

Rifiotis (2014) afirma que não há um processo contínuo entre lei, direito e justiça, pois as lutas por reconhecimento, quando dirigidas ao judiciário, produzem outro processo de tradução dessas demandas. A efetivação de um direito está condicionada a interpretação realizada no campo jurídico e, sendo um campo aberto a disputas de sentido e legitimidade por um conjunto variado de agentes e órgãos, é importante, como aponta Schuch (2008), dar atenção aos processos de constituição de sentidos, investigando como os direitos são institucionalizados a partir da prática dos agentes e dos órgãos do campo judicial.

\section{Direito fazendo gênero}

Como exposto anteriormente, o Brasil, por não possuir uma legislação específica que regule o direito à identidade, orienta-se por uma perspectiva autorizativa porque há necessidade de entrar com ação judicial para obter a autorização de mudança do nome e gênero em seus documentos. Bento (2008) realiza a distinção entre perspectiva de reconhecimento e a autorizativa para destacar que há países onde o direito das pessoas trans é reconhecido em lei, enquanto outros casos, como o brasileiro, há necessidade de autorização judicial para que o direito se materialize.

Nesse sentido, o estudo sobre o modo como o tema em tela é tratado pelos operadores do direito se faz importante, dado que a efetivação depende da interpretação dos julgadores. Alguns estudos têm proposto uma discussão, a partir da análise de decisões de apelação em tribunais estaduais, sobre como se tem interpretado a demanda de retificação e pensar até que ponto as decisões apoiam-se em princípios jurídicos e legislações nacionais e/ ou supranacionais ou, então, a partir de elementos extra-legais ${ }^{4}$. Esses autores

$4 \quad$ Utiliza-se o termo extra-legal no sentido dado por Sandalowski (2005) ao estudar, em sua dissertação de mestrado, as categorias acionadas pelos operadores do direito no que tange à violência doméstica contra crianças e adolescentes, demonstrando que estes acionam o seu modelo de interpretação da realidade social, isto é, elementos extra-legais para decidir sobre a gravidade da denúncia apresentada pelo Ministério Público. 
demonstraram, ao estudarem os acórdãos envolvendo demandas de pessoas trans, que o discurso jurídico aciona categorias médicas e psicológicas em sua argumentação sobre a transgeneridade, seja em uma perspectiva alinhada aos direitos humanos, seja em uma perspectiva patologizante (COACCl, 2011; ZAHRA \& BECKER, 2014; MOURA, 2015; LIMA, 2015).

Moura (2015), em análise de 25 acórdãos de pleitos para a retificação do registro civil, procura se a jurisprudência majoritária à demanda, identificando as principais categorias que são acionadas pelos desembargadores de tribunais estaduais para fundamentar as decisões sobre retificação do registro civil, entre janeiro de 2009 e julho de 2015. Observa que nos 21 casos de pessoas trans que solicitaram a alteração, seja apenas do nome ou do nome e gênero, e não passaram por processo transexualizador, 11 pedidos em que houve pedido apenas da alteração do nome, seis foram deferidos e cinco não. Quando o pedido era a retificação do nome e também do gênero, das 10 solicitações, em cinco pedidos a demanda de retificação foi integralmente acatado, quatro foram integralmente rejeitados e um concedeu-se apenas a retificação do nome. Quando verificada o motivo do indeferimento, é a não realização da cirurgia de redesignação sexual a razão para a negativa da retificação.

Coacci (2011), em um estudo descritivo de 10 apelações de retificação, entre os anos de 2008 a 2010, identifica a forma como a questão é analisada no TJ de Minas Gerais. Destaca que os argumentos favoráveis e contrários dos desembargadores que julgaram os casos tiveram os pedidos negados ou acatados a partir dos seguintes critérios: das 7 que eram de retificação de registro civil (três foram negados retificação do gênero e duas com sentença em primeiro grau cassada) o argumento para indeferimento alegava impossibilidade jurídica de mudar a biologia; os casos em que foi deferido a retificação de gênero, as pessoas já haviam passado pelo processo transexualizador; aqueles que tiveram a demanda de retificação de nome acolhidos, baseiam-se em princípios da dignidade humana, direito à personalidade e a proteção a constrangimentos, mas o discurso patológico ainda foi acionado para falar de uma condição transexual nos moldes do saber médico.

Lima (2015), segue uma questão semelhante a de Coacci (2011), na busca em pensar as diversas justificativas dadas para posicionamentos favoráveis ou contrários à retificação dos documentos. A partir da análise de apelações em tribunais estaduais de justiça de todo o país, procura indicar uma série de "porquês" passando pela produção de verdades sobre o sexo verdadeiro na materialização da transexualidade, naquela pleiteia a retificação, o saber médico aqui foi acionado pelos operadores do direito. As leis e princípios jurídicos foram acionados e a autora concentra-se naqueles em que observou a preocupação de operadores do direito sobre a possibilidade de pessoas trans prejudicarem ou enganarem a terceiros, na probabilidade de casamento e formação de família, e, portanto, devem ter seus direitos garantidos. 
Zahra e Becker (2014), em estudo de acórdãos do TJRS, analisam 14 pleitos de retificação do registro civil, majoritariamente acatados, contudo a partir de discursos médicos. O diagnóstico de disforia/transtorno de identidade de gênero aparece como uma das categorias que fundamenta as decisões dos pedidos das pessoas trans que acessam a justiça para os processos de retificação. Nos casos analisados, ainda que haja a garantia da autodeterminação de gênero, sem condicionar a cirurgia, considerando os princípios fundamentais, há a permanência do discurso médico e psicológico da patologização da identidade de gênero nas interpretações de operadores do direito. As autoras destacam que a transgeneridade e a demanda social por reconhecimento da identidade de gênero passam por um entrelaçamento dinâmico, em que o discurso biomédico é acionado conjuntamente com princípios jurídicos.

A diferença desse trabalho em relação aos demais é o foco em um estudo de caso dos votos de indeferimento. Analisou-se os recursos de apelação números 70030823587 (Apelação I), 70056132376 (Apelação II), 70064503675 (Apelação III), 70066291360 (Apelação IV), 70068173962 (Apelação V) e 70067749291 (Apelação VI) ${ }^{5}$. Observou-se que todos os desembargadores, com exceção da apelação VI, realizaram suas reflexões de acordo com concepções de gênero a partir da perspectiva de autoidentificação sob o determinismo biológico, baseado em elementos psicossociais.

Em relação ao teor dos votos relativos ao mérito dos recursos proferidos pelos Desembargadores nas referidas apelações, verifica-se a ocorrência de apropriação de termos e documentos das ciências médicas como definidores dos corpos normais (mulher com vagina e homem com pênis) e os corpos anormais e patológicos (mulheres com pênis e homens com vagina), definindo-se e sendo exigido pelos julgadores, em razão disso, a correção desses corpos (cirurgia de transgenitalização) para que os direitos do indivíduo sejam tutelados pelo Estado.

Chama atenção o teor dos votos proferidos nas Apelações III, IV e VI o discurso binário e essencialista de gênero operando nas decisões, como se observa no voto Apelação III:

[...] o recorrente não é mulher e o registro público espelha a verdade biológica, admitindo-se, como exceção, a troca de sexo quando existe prévia cirurgia de transgenitalização. Ou seja, quando há adequação da sua forma física ao gênero sexual a que pertence. [...] A definição do sexo é ato médico e o registro civil de nascimento deve sempre espelhar a verdade, que é a biológica. E somente pode ser corrigido o registro quando se verifica existência de erro. Com a realização da cirurgia, ocorrendo a transgenitalização, verifica-se uma situação excepcional, ou seja, há o ato médico redefinindo o sexo e atestando a inadequação do registro, que deverá então ser corrigido. [...] tenho que é des-

$5 \quad$ Ressalta-se, todavia, que a não possibilidade de acesso ao inteiro teor dos fundamentos utilizados pelos apelantes nos recursos de apelação ora analisados, dificultam a análise completa de tais argumentos, uma vez que o que abaixo está consignado é fruto da apreciação dos julgadores, que mencionaram os elementos que consideraram relevantes ao julgamento do feito e talvez não todos os de fato expostos nas manifestações. 
cabida a alteração do registro civil para fazer constar dado não verdadeiro, isto é, que o autor seja do sexo feminino, quando inequivocamente ele é do sexo masculino, pois ostenta órgão genitais tipicamente masculinos. [...] entendo que não é a vontade do recorrente de ser mulher, nem o fato de se sentir mulher, que o transforma em mulher. Pode parecer mulher, mas mulher ele não é. [...] observo que a sexualidade é questão biológica e que transcende o plano da vontade individual, e a definição do sexo constitui ato médico. $\mathrm{E}$, como o registro civil de nascimento deve espelhar a verdade biológica, somente poderá ser corrigido quando se verificar erro. $E$, no caso em exame, erro não existe. E certamente não será a mera alteração formal do registro civil que transformará magicamente o autor, que é homem, em mulher (Voto do relator, Desembargador, Sérgio Fernando de Vasconcellos Chaves, Apelação Cível n 70064503675).

Verifica-se que a maioria dos Desembargadores utilizaram discursos deterministas e com base em uma concepção binária sobre o sexo como única possibilidade possível para o gênero, o que reatualiza as normas excludentes que produzem a marginalização das variadas formas de experienciar e viver o gênero. Assim, como as pesquisas de Coacci (2011), Zahra e Becker (2014), Moura (2015) e Lima (2015), esse estudo observa que o "sexo jurídico", que consta no assento de nascimento e é pleiteado retificação, para os operadores do direito, reflete uma "realidade" biológica que na argumentação será indicada em diferentes níveis, seja genético ou fenotípico.

O que para o campo jurídico refletiria uma realidade, corroborada por saberes exteriores, como a medicina, na realidade é uma tecnologia de produção de corpos ou, nas palavras de Lauretis (1994), uma tecnologia de gênero que produz, estabiliza e reatualiza as normas de gênero binário. Para a autora, gênero é uma representação que tem efeitos concretos, tanto sociais quanto subjetivos, que constroem nos mais diversos espaços e práticas, inclusive no campo jurídico, "realidades".

A querela no direito é justamente uma disputa de validade e legitimidade entre discursos, elevando, ao final do processo, uma das posições (ou outra nova, criada no percurso) ao status de "verdade". O que está em jogo em um processo não é apenas aquele caso em tela, mas uma relação de saber e poder. Essa relação é mais marcante nos processos de segunda instância, pois são julgamentos colegiados, proferidos, em regra, por três desembargadores/as. Além disso, suas decisões se tornam públicas e são frequentemente referenciadas em outras decisões, trabalhos acadêmicos e manuais de direito, podendo, inclusive, fundar novos paradigmas jurídicos. A jurisprudência tem um poder, ao ser repetidamente referenciada, de solidificar uma forma de entender/compreender o direito (COACCl, 2011, p. 90).

O direito não está imune à matriz de inteligibilidade de gênero marcada pelo dualismo sexo/gênero, pois se trata também de uma prática social que legitima a ordem social vigente. Estudando os votos de indeferimento, fica claro que o discurso jurídico reatualiza as normas de gênero quando aciona categorias médicas para falar da transgeneridade. $O$ ato de dizer que sexo é um ato médico e que o registro civil deve sempre espelhar uma verdade, que é biológica e não seria a vontade da apelante que a transformaria em mulher, 
tendo em vista sua genitália, mostra a citacionalidade das normas regulatórias. $\mathrm{O}$ ato de dizer produz aquilo que se fala, então, cada voto fabrica uma realidade, constituindo um campo de inteligibilidade, em que as pessoas trans são materializadas como sujeitos viáveis a acessar o direito à identidade.

As normas de gênero, como afirma Butler (2001), se fossem naturais e fixas não precisariam a todo instante serem citadas e, portanto, reafirmadas. É justamente pelo seu caráter construído que é preciso reiterá-las cotidianamente em diferentes espaços, discursos e práticas sociais que demarcam fronteiras entre o que é ser homem e ser mulher.

Butler (2008) entende o gênero enquanto uma prática discursiva e performática do corpo por meio do qual o indivíduo adquire inteligibilidade social e reconhecimento político. Então, aquilo que é referenciado pelos desembargadores como uma verdade, são efeitos de instituições, práticas e discursos. O sexo também é o meio como a 'natureza sexuada' ou um 'sexo natural' é produzido e entendido como pré-discursivo, ou seja, como anterior à própria cultura, isto é, corpos, processos psicológicos, partes dos corpos não tem sentido fora de uma compreensão social (BUTLER, 2001).

Moore (1997), afirma que o ocidente entende a diferença anatômica como um dado autoevidente porque entenderia alocada na natureza. O modelo nativo ocidental de gênero, proveniente da ciência biomédica, toma o sexo como pré-social e atrela gênero a anatomias particulares. As implicações disso é pensar que a biologia é estável e fixa, então, essencial para a divisão do mundo social, e compreensão do que é ser homem e mulher faz escorregar para um determinismo biológico. Mas argumenta, citando Fauto-Sterling, que pesquisas na área da biologia têm demonstrado que a relação entre biologia e comportamento social é uma relação de causa-efeito, porque se trata de um componente dinâmico e não determinante.

Como argumenta a autora, as formas de compreensão do que seja gênero são histórica, política e culturalmente variáveis. É um campo político de disputas, conforme Scott (1985), em que o poder se manifesta, constituindo significados e organizando de forma hierárquica e dinâmica as relações de gênero. Enquanto um campo político, gênero inscreve-se como uma dimensão fixa e permanente da diferença sexual, eclipsando seu caráter histórico e localizado. Articulando uma dimensão política ao gênero, a autora:

Se tratamos a oposição entre homem e mulher como problemática e não como conhecida, como algo que é contextualmente definido, repetidamente construído então devemos constantemente perguntar não apenas o que está em jogo em proclamações ou debates que invocam o gênero para explicar ou justificar suas posições, mas também como compreensões implícitas de gênero que estão sendo invocadas ou reinscritas (SCOTT, 1985, p. 93). 
A questão é pensar como o campo jurídico produz verdades sobre gênero, em que, nas palavras de Coacci (2011, p. 90), "o direito e os juízes exercem uma função: ser fiscal e guardião do sexo e do gênero, de uma lei que não está em lugar algum, mas ao mesmo tempo está em todo lugar". Esse campo, portanto, é atravessado pela matriz cisgênera e heteronormativa.

\section{4 (En)gendrando o direito à identidade: a materialização da transexualidade}

É cristalina a exigência dos julgadores para que as pessoas trans realizem a cirurgia para a modificação de seus corpos e de provas robustas da transexualidade, estas entendidas como aquelas produzidas por médicos psiquiatras, que atestem a existência da patologia e de erro a ser corrigido, observados nos votos da Apelação II:

No presente caso, embora Marcos há longo período venha se submetendo a acompanhamento por equipe de especialistas do Hospital de Clínicas, consoante se observa dos históricos de atendimentos médicos juntados às fls. 19 a 40, não há previsão de realização da cirurgia de modificação de seus órgãos sexuais, nem mesmo recomendação de eventual procedimento cirúrgico. Mais: ainda que tenha aparência masculina, como demonstram as fotos juntadas à fl. 09, e tenha relatado as dificuldades que encontra na vida diária, em especial quando precisa do certificado de reservista, inexiste esclarecimentos detalhados e concretos acerca da anatomia de seus órgãos sexuais, nem laudos elaborados pelos médicos, psiquiatras ou psicólogos que o atenderam durantes todos esses anos, que referissem, com precisão técnica, a abrangência do transtorno de identidade sexual, mencionando no documento da fl. 32 (Voto do relator, Desembargador, Jorge Luís Dall' Agnol, Apelação Cível n 70030823587).

Afirma que pretende futuramente, após submeter-se à cirurgia buscar a alteração de sexo, para tornar-se uma pessoa normal dentro do contexto social, sem ser vista com discriminações. [...] Parece-me bastante claro, pelo que os autos mostram, trata-se de uma pessoa transexual, que rejeita sua sexualidade natural e tem como meta ou fantasia a correção cirúrgica da sua genitália, que sente-se mulher, vive como mulher e sonha como mulher, acreditando mesmo pertencer ao sexo contrário ao da sua conformação anatômica. [...] não é possível modificar o seu sexo, pois não se submeteu à cirurgia de redefinição sexual. Ou seja, não se trata de pessoa do sexo feminino, ainda que exteriorize tal comportamento, tanto que, para evitar situações de constrangimento, foi deferido a ele a troca de nome (Voto do revisor, Desembargador, Sérgio Fernando Vasconcellos Chaves, Apelação Cível n 70030823587). 
Nessa mesma linha são proferidos os votos das Apelações I, III e V, pois para o Relator a não realização de cirurgia de redesignação sexual, aliada à ausência de "esclarecimentos detalhados e concretos acerca da anatomia de seus órgãos sexuais, nem laudos elaborados pelos médicos, psiquiatras ou psicólogos" impossibilitam o reconhecimento do direito à identidade de gênero. Fica claro que os desembargadores operam por uma matriz binária que assume como verdade a coerência sexo-gênero, em que analisa o requerente como alguém que não "se encaixa em seu sexo" (Apelação V, Voto do relator, Desembargador, Jorge Luís Dall' Agnol). Percebe-se o controle dos corpos através de uma matriz cisgênera, fundamentada no determinismo biológico (existência de pênis e vagina), e legitimada através de documentos médicos que patologizam os corpos que transcendem tais conceitos objetivos, deterministas e reducionistas sobre a identidade de gênero, tais como as pessoas trans e as intersexuais.

Para Bagagli (2013), a matriz cisgênero possibilita refletir sobre uma máquina de produção de corpos, tanto cisgêneros quanto transgêneros ${ }^{6}$. Essa matriz demarca a hierarquização entre as identidades, aduzindo que as primeiras são naturalizadas e consequentemente compreendidas enquanto destino dos corpos, na medida em que as últimas, instituídas como desviantes e anormais, são patologizadas pelos discursos médicos e jurídicos. Atravessa por essa matriz, o saber jurídico juntamente com os saberes médicos e psicológicos reatualizam o que Bento (2006) chama de dispositivo da transexualidade, transformando a ideologia de gênero em saber científico e jurisdicional, apagando multiplicidades de sujeitos e transformando as experiências de deslocamento de gênero em "disfóricos".

A categoria transexual emerge a partir da intervenção dos discursos médicos e das ciências psicológicas, delimitando o que é considerado normal do que é considerado patológico no âmbito das identidades de gênero, porque se supõe, como coloca Bento (2008), se tratar de um conflito identitário que ocorre em decorrência da inconformidade das pessoas trans ao próprio corpo e não um produto da matriz cisgênera. Esse processo torna-se um instrumento de controle dos indivíduos porque tudo que transita entre e para além dos gêneros na ideologia de gênero vigente foi classificada como transtorno de identidade de gênero e, mais recentemente, como disforia de gênero, o qual, a ciência médica elenca uma série de critérios que as pessoas trans devem passar para receberem o diagnóstico (ARÁN, 2010; BENTO, 2010; BUTLER, 2009).

O Conselho Federal de Medicina do Brasil, através da Resolução n 1.955 de 12 de agosto de 2010, disciplina a realização da cirurgia de transgenitalismo e em seu art. 3 estabelece critérios mínimos no diagnóstico do transexual, quais sejam: 1) Desconforto com o sexo anatômico natural; 2) Desejo expresso de eliminar os genitais, perder as características primárias e secundárias do próprio sexo e ganhar as do sexo oposto; 3) Permanência desses distúrbios de

$6 \quad$ Cisgeneridade é utilizado para classificar a mútua identificação entre gênero e sexo, ou seja, entre a identificação psicossocial de gênero e a genitália do indivíduo. Também é um fator que produz e institui a diferença, a transgeneridade, corpos que transcendem a identificação sexo/gênero (JESUS, 2014). 
forma contínua e consistente por, no mínimo, dois anos; 4) Ausência de outros transtornos mentais. $\mathrm{O}$ art. 4 da mesma Resolução, por sua vez, estabelece os critérios mínimos para a realização da cirurgia de transgenitazação, quais sejam: "1) Diagnóstico médico de transgenitalismo; 2) Maior de 21 (vinte e um) anos; 3) Ausência de características físicas inapropriadas para a cirurgia".

Butler (2009) afirma que a avaliação diagnóstica realizada por profissionais da saúde a partir de critérios como esse visa a verificar se o indivíduo consegue se adequar ao discurso psicológico, à linguagem do diagnóstico. Aspecto que Bento (2008) demonstra ocorrer em sua pesquisa quando as pessoas trans em processo transexualizador adequavam o seu discurso ao modelo biomédico para acessarem à cirurgia, ainda que vivessem uma multiplicidade de experiências que divergiam do esperado pelos critérios diagnósticos.

Coacci $(2011$, p. 88$)$ a respeito de sua pesquisa destaca que

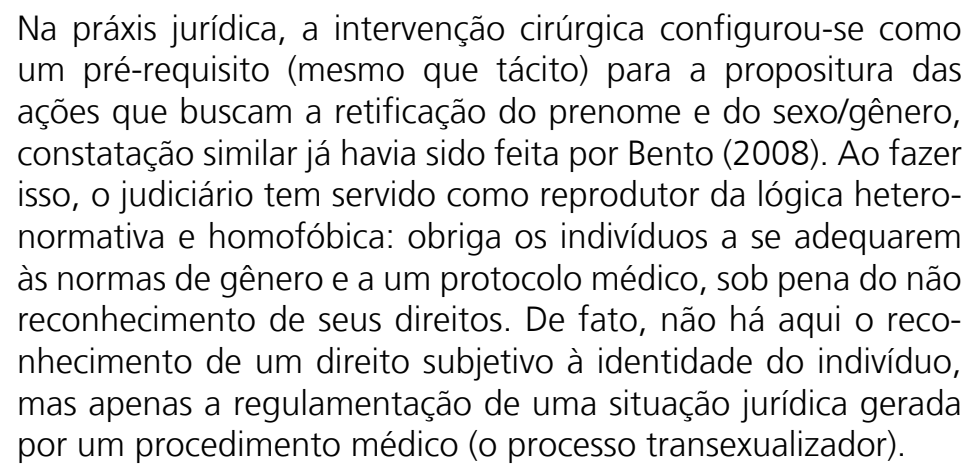

A exigência de laudos médicos psiquiátricos, a fim de atestar algo que é ou deveria ser autodeterminado pelo indivíduo, também legitima a violência simbólica do campo jurídico, que (en)gendra pessoas trans, isto é, produz a transexualidade. O Direito como uma tecnologia de gênero (LAURETIS, 1994) produz os corpos como transexuais a partir de um aparato sexo-semiótico que subjetiva e materializa-se quando os indivíduos passam a tomar a representação para si, isto é, como autorepresentação, dando significado para indivíduos viverem em sociedade, constituindo seus corpos e estabelecendo posições de sujeito.

Os operadores do direito reproduzem a exigência de determinados requisitos das pessoas trans para reconhecerem as suas identidades. Observa-se que a narrativa das pessoas que pleitearam submete suas demandas à essa lógica patologizante, quando nas apelações (I, II, IV e V) fazem referência expressa sobre o tratamento hormonal e ao processo transexualizador. $\mathrm{Na}$ apelação I, o requerente refere não ter realizado a cirurgia de transgenitalização, mas estar realizando o acompanhamento junto ao PROTIG, no Hospital de Clínicas de Porto Alegre; na apelação II, o apelante informa ser "portador de Transtorno de Identidade Sexual" e realizar a hormonização desde a sua adolescência, bem como ter feito várias cirurgias para adequar seu corpo à sua identidade de gênero; na apelação IV, relata que está em fase preparatória à 
cirurgia e realizando tratamento hormonal; na apelação $V$, refere ter sua transexualidade comprovada através de laudos médicos, porém, só não obteve êxito até o momento na realização da cirurgia, em razão de ser portador de trombose na perna direita.

De outra banda, há argumentações dissidentes, ainda que de forma tímida e sem abandonar totalmente o viés patologizante da transgeneridade, como se observa nos votos da Desembargadora Sandra Brisolara Medeiros na Apelação III e os votos do Desembargador Jorge Luis Dall' Agnol nas Apelações IV e VI.

A Desembargadora Sandra, revisora da Apelação III, inicia a construção do seu voto distinguindo sexo e gênero e trazendo elementos para a definição do indivíduo transexual. De forma diligente, também apresenta referenciais teóricos na construção do seu voto, concluindo que o gênero, ao seu ver, entendido enquanto identificação psicossocial do indivíduo, deve prevalecer sobre o sexo biológico, sendo inadmissível exigir do indivíduo a realização do processo transexualizador, porquanto esta pode não ser desejada pelo indivíduo ou a ele não indicada em razão de outros fatores médicos. O Desembargador Jorge Luis Dall' Agnol, nas Apelações IV e VI, parece ter alterado o seu entendimento, ao passo que abandona o discurso determinista biológico e passa a enxergar gênero enquanto discurso e manifestação dos corpos, bem como enquanto identificação psíquica com determinado gênero. Mas ambos são votos vencidos e os pedidos foram indeferidos.

\section{Conclusão}

Essa análise demonstra a ocorrência de utilização de elementos extralegais pelos julgadores, em especial das suas representações sobre o que significa "ser homem" e "ser mulher" e da apropriação do conhecimento médicos, para embasar as decisões. O Direito atua intensamente no que Foucault (2007) chamou de disciplinarização de corpos, ou seja, o Direito realiza, através de seus atos nutridos de aparente legitimidade, a modelagem e o controle dos corpos, ditando, com base nos discursos hegemônicos, quais corpos serão normais e quais corpos serão anormais. O Poder Judiciário, ao passo que não se exime de analisar os pedidos de alteração de nome e gênero de pessoas trans, nas demandas aqui vistas, ao analisar a questão trans unicamente pelo viés patológico e determinista biológico, deixa de lado direitos constitucionais e internacionais que custaram caro às gerações ocidentais contemporâneas.

Percebe-se no teor da maioria dos votos das apelações aqui analisadas que, em que pese o conhecimento dos operadores do direito sobre o ordenamento jurídico vigente, em especial sobre o processo histórico da construção dos direitos humanos, bem como o processo histórico que levou à elaboração da Constituição Federal de 1988, os Desembargadores, em sua maioria, sequer aventam vislumbrar as demandas pelo viés dos direitos fundamentais e humanos. Outrossim, verifica-se a ausência de enfrentamento normativo legal 
da temática, uma vez que os desembargadores não aventam prestar a tutela jurisdicional sob o viés normativo constitucional e internacional.

Como já mencionado, o direito, principalmente através das decisões judiciais e interpretações normativas, contribui largamente no processo de construção de corpos dóceis e domesticados, pois acredita ser legitimado pelo Estado a dizer e delimitar corpos saudáveis e corpos anormais, produzindo, como visto na fundamentação, tecnologias de gênero, pois auxiliam na manutenção e criação de normas delimitadoras sobre o "ser homem" e o "ser mulher".

Ressalta-se que, ainda que reconhecida a importante produção de saberes pelas ciências médicas, em especial no alívio do sofrimento da população trans através das terapias hormonais e cirúrgicas que possibilitam uma maior aproximação dessas pessoas à aparência do gênero de identificação, a manutenção da patologização desses indivíduos perpetua e muitas vezes legitima as diversas violências praticadas pela sociedade e pelo próprio Estado, aqui visto com ênfase na atuação do Poder Judiciário. Pois, como visto acima, os operadores do direito utilizam como maior fundamento no não reconhecimento ao direito à identidade de gênero o discurso médico sobre o ser homem e o ser mulher, exigindo, em todos os casos, laudos médicos psiquiátricos que comprovem a extensão da patologia nesses sujeitos e a intervenção cirúrgica para a alteração de seus órgãos genitais.

Assim, denota-se que a inércia dos nossos legisladores sobre a matéria em análise não pode ser ignorada e subestimada, porquanto ela acaba corroborando no processo de marginalização da população trans, mantendo a pessoa trans invisível perante o Estado e suas instituições de poder. Esse fato também contribui na manutenção e no aumento de violência e discriminação, ao passo que a ausência de manifestação legislativa sobre a matéria fomenta o imaginário social de que esses indivíduos não são detentores de direitos, bem como, contribui para que os intérpretes e aplicadores do ordenamento jurídico utilizem de forma majoritária suas concepções subjetivas quando deparam-se com tal temática.

Outrossim, havendo disposições legislativas gerais de nível constitucional e internacional, tais como os princípios da dignidade da pessoa humana, da liberdade, da igualdade, da intimidade, os Princípios de Yogyakarta e as demais disposições referente aos Direitos Humanos, parece que a construção das decisões judiciais aqui analisadas destoam daquilo que é esperado do Poder Judiciário na prestação da tutela jurisdicional, com maior razão em situações em que o judiciário acaba sendo o único instrumento capaz de conferir visibilidade, humanidade, dignidade e respeito a determinadas pessoas.

Nas apelações aqui mencionadas, pode-se perceber que os Desembargadores que nelas atuaram, em movimento contrário ao aderido e previsto na Constituição Federal de 1988 e nos Direitos Humanos, principalmente quando aplicados sob a ótica dos Princípios de Yogyakarta, contribuíram e legitimaram a patologização das pessoas trans, fato este que em seu efeito colateral gera mais invisibilidade, mais preconceito, mais discriminação, mais marginalização, 
mais dificuldade de acesso ao mercado de trabalho, mais dificuldade de permanência nas instituições de ensino, enfim, mais violência praticada e legitimada pelo próprio Estado, o qual possui o dever constitucional de proteger e garantir condições dignas à todos os seres humanos.

Desta forma, ainda que tenhamos vislumbrado dois votos que fizeram referência aos supramencionados direitos e princípios constitucionais, tais argumentos restaram vencidos pelos votos construídos através da subjetividade dos Desembargadores, os quais, mediante a apropriação de saberes médicos e biológicos, vão ao encontro da visão patologizante dos homens e mulheres transexuais.

\section{Referências}

ARÁN, Márcia. A saúde como prática de si: do diagnóstico de transtorno de identidade de gênero às redescrições da experiência da transexualidade. In: ARILHA, M.; LAPA, T. S.; PISANESCHI, T. C. (Orgs.). Transexualidade, Travestilidade e Direito à Saúde. São Paulo, Oficina Editorial, 2010.

BAGAGLI, Beatriz Pagliarini. Máquinas discursivas, ciborgues e Transfeminismo. Revista Gênero, Niterói, v.14, n.1, p. 11-27, 2013.

BENTO, Berenice A reinvenção do corpo: sexualidade e género na experiência transexual. Rio de Janeiro: Garamond, 2006.

. O que é transexualidade. São Paulo: Brasiliense: 2008.

. Gênero: uma categoria cultural ou diagnóstica? In: ARILHA, M.; LAPA, T. S.; PISANESCHI, T. C. (Orgs.).

Transexualidade, Travestilidade e Direito à Saúde. São Paulo, Oficina Editorial, 2010.

. Nome social para pessoas trans: cidadania precária e gambiarra legal. Contemporânea, Revista de Sociologia da UFSCar, v. único, p. 165-185, 2014.

BUTLER, Judith. Corpos que pesam: sobre os limites discursivos do "sexo". In: LOURO, Guacira Lopes.(org.). O corpo educado: pedagogias da sexualidade. Belo Horizonte: Autêntica, 2001.

Problemas de Gênero: feminismo e subversão da identidade. Rio de Janeiro, Ed. Civilização Brasileira, 2008.

Desdiagnosticando o gênero. Physis, Rio de Janeiro, v. 19, n. 1, 2009.

COACCI, T. A transexualidade no/pelo Judiciário mineiro: um estudo dos julgados do TJMG correlatos à transexualidade no período de 2008 a 2010. Revista Três Pontos, Belo Horizonte, v. 8, n. 2, p.81-92, 2011.

CONSELHO FEDERAL DE MEDICINA. Resolução CFM 1.955/2010. Brasília, 2010. Disponível: http://www. portalmedico.org.br/resolucoes/CFM/2010/1955_2010.htm. Acessado em: 14 mai. 2017.

DEBERT, G. G. Desafios da politização da Justiça e a Antropologia do Direito. Revista de Antropologia, São Paulo, USP, v. 53, n. 2, p. 475-492, 2010.

FOUCAULT, Michel. História da Sexualidade: A vontade de saber. Vol. 1. Rio de Janeiro: Edições Graal, 2007.

JESUS, Jaqueline Gomes. Gênero sem essencialismo: feminismo transgênero como crítica do sexo. Universitas Humanistica, v. 78, p. 241-258, 2014

LAURETIS, Teresa de. A tecnologia do gênero. In: HOLLANDA, H. B. Tendências e impasses: o feminismo como crítica da cultura. Rio de Janeiro: Rocco, 1994.

LIMA, L. F. A "verdade" produzida nos autos: uma análise de decisões judiciais sobre retificação de registro civil de pessoas transexuais em Tribunais brasileiros. Dissertação de Mestrado, Programa de Pós-Graduação em Antropologia Social, Universidade de São Paulo, São Paulo, 2015.

MOORE, Henrieta. Compreendendo Sexo e Gênero. In: INGOLD, Tim (Ed.). Companion Encyclopedia of Anthropology. Londres: Routledge, 1997, p. 813-830. 
MOURA, M. L. Análise jurisprudencial em demandas por retificação registral de transexuais. Âmbito Jurídico, XVIII, n. 142, 2015.

RIFIOTIS, T. Judiciarização das relações sociais e estratégias de reconhecimento: repensando a "violência conjugal" e a "violência intrafamiliar". Revista Katálysis, Florianópolis, v. 11, n. 2, p. 225-236, 2008. Judicialização dos direitos humanos, lutas por reconhecimento e políticas públicas no Brasil: configurações de sujeito. Revista de Antropologia, São Paulo, v. 57, n. 1, p. 119-144, 2014.

. Violência, Justiça e Direitos Humanos: reflexões sobre a judicialização das relações sociais no campo da "violência de gênero". Cadernos Pagu, Campinas, a. 45, p. 261-295, 2015.

; MATOS, M. Judicialização, direitos humanos e cidadania. In: FERREIRA, L. F. G.; ZENAIDE, M. N. T.; PEREIRA, C. M. C.; SILVA, I. N. (Orgs.). Direitos Humanos na Educação Superior: Subsídios para a Educação em Direitos humanos nas Ciências Sociais. João Pessoa: Editora Universitária da UFPB, 2010. p. 241-287.

RIO GRANDE DO SUL, Apelação Cível N 70030823587, Sétima Câmara Cível, Tribunal de Justiça do RS, Relator: Jorge Luís Dall'Agnol, Julgado em 23/06/2010, Disponível em: http://bit.ly/2rT462P. Acesso em: 15/03/2017.

RIO GRANDE DO SUL. Apelação Cível No 70056132376, Sétima Câmara Cível, Tribunal de Justiça do RS, Relator: Jorge Luís Dall'Agnol, Julgado em 13/11/2013. Disponível em: http://bit.ly/2sozZwX. Acesso em: 15/03/2017

RIO GRANDE DO SUL. Apelação Cível N 70064503675, Sétima Câmara Cível, Tribunal de Justiça do RS, Relator: Sérgio Fernando de Vasconcellos Chaves, Julgado em 24/06/2015. Disponível em: http://bit.ly/2rG8ToR. Acessado em: 15/03/2017.

RIO GRANDE DO SUL. Apelação Cível N 70066291360, Sétima Câmara Cível, Tribunal de Justiça do RS, Relator: Jorge Luís Dall'Agnol, Redator: Sérgio Fernando de Vasconcellos Chaves, Julgado em 16/12/2015. Disponível em: http://bit.ly/2qHgmiw. Acesso em: 15/03/2017.

RIO GRANDE DO SUL. Apelação Cível N 70067749291, Sétima Câmara Cível, Tribunal de Justiça do RS, Relator: Jorge Luís Dall'Agnol, Redator: Sérgio Fernando de Vasconcellos Chaves, Julgado em 18/05/2016. Disponível em: http://bit.ly/2sfjoMF. Acesso em: 15/03/2017.

RIO GRANDE DO SUL. Apelação Cível No 70068173962, Sétima Câmara Cível, Tribunal de Justiça do RS, Relator: Jorge Luís Dall'Agnol, Julgado em 16/03/2016. Disponível em: http://bit.ly/2rco1J2. Acesso em: 15/03/2017

SANDALOWSKI, M. C. O tratamento dado à violência doméstica contra crianças e adolescentes pela justiça criminal: estudo de caso em Santa Maria. Dissertação (Programa de Pós-Graduação em Sociologia - Mestrado e Doutorado), Universidade Federal do Rio Grande do Sul. 2005.

SCHUCH, P. A "judicialização do amor": sentidos e paradoxos de uma justiça "engajada", Campos, Curitiba, n. 9, p. 8-29, 2008.

SCOTT, Joan. Gênero: uma categoria útil de análise histórica. Revista Educação e Realidade, v. 20, n. 2, p. 71-99, 1995.

SCOTT, J. C. Seeing like a state: how certain schemes to improve the human condition have failed. Nova Haven: Yale University Press, 1998.

SUESS, A. Cuestionamiento de dinámicas de patologización y exclusión discursiva desde perspectivas trans e intersex. Revista de Estudios Sociales, n. 49, p. 128-143, 2014.

ZAHRA, V. M. M.; BECKER, S. As representações das(os) transexuais nas aldeias arquivos do TJRS: o Poder da nomeação, eis a grande questão. Pensata Revista dos Alunos do Programa de Pós-Graduação em Ciências Sociais da UNIFESP, v. 4, p. 69-92, 2014. 